\title{
Karakterisasi Sifat Magnetik Dan Sifat Listrik Endapan Sinter di Beberapa Sumber Mata Air Panas Sumatera Barat (Studi Kasus: Mata Air Panas Alam Pauh Duo Kabupaten Solok Selatan, Sumani Kabupaten Solok dan Bonjol Kabupaten Pasaman Sumatera Barat)
}

\author{
Afdal Fajri Salim*, Arif Budiman, Ardian Putra \\ Laboratorium Fisika Bumi, Jurusan Fisika, FMIPA, Universitas Andalas \\ Kampus Unand, Limau Manis, Padang, 25163 \\ *afdalfs@gmail.com
}

\begin{abstract}
ABSTRAK
Telah dilakukan karakterisasi sifat magnetik dan sifat listrik endapan sinter mata air panas dari mata air panas Sapan Malulung Kabupaten Solok Selatan, Sumani Kabupaten Solok dan Bonjol Kabupaten Pasaman. Pengukuran resistivitas listrik dilakukan dengan metode dual probe electrode dan suseptibilitas magnetik dengan menggunakan metode anisotropy of magnetic susceptibility (AMS). Nilai suseptibilitas magnetik yang didapatkan dari seluruh endapan sampel adalah $6 \times 10^{-8} \mathrm{~m}^{3} / \mathrm{kg}-15 \times 10^{-8} \mathrm{~m}^{3} / \mathrm{kg}$. Diperkirakan mineral magnetik yang berkontribusi di dalam nilai suseptibilitas magnetik adalah hematit. Rendahnya nilai suseptibilitas magnetik di dalam endapan sinter dikarenakan oleh jumlah mineral magnetik (hematit) yang terkandung di dalam endapan sinter. Nilai resistivitas listrik tidak jenuh air didapatkan pada kisaran 35,632 $\Omega \mathrm{m}$ dan 2509,569 $\Omega \mathrm{m}$. Besarnya rentang nilai resistivitas listrik yang didapatkan karena ketiadaan mineral konduktif di dalam endapan sinter. Nilai resistivitas listrik jenuh air didapatkan pada kisaran 6,829 $\Omega \mathrm{m}$ sampai 49,333 $\Omega \mathrm{m}$. Tingginya nilai resistivitas listrik ini dikarenakan terdapatnya material-material pengotor yang tidak berasal dari reservoir panas bumi. Nilai suseptibilitas magnetik endapan sampel pada ketiga lokasi meningkat terhadap penurunan temperatur permukaan atau bila menjauhi mata air panas, sedangkan resistivitas listrik memiliki bentuk perubahan yang acak terhadap penurunan temperatur.

Kata kunci: endapan sinter mata air panas, resistivitas listrik, suseptibilitas magnetik, panas bumi
\end{abstract}

\begin{abstract}
Magnetic and electrical properties characterization of sinter deposits at several hot springs in Solok Selatan, Solok and Pasaman District has been conducted. Measurement of the electrical resistivity using dual probe electrode method and the magnetic susceptibility using anisotropy of magnetic susceptibility (AMS) method. Magnetic susceptibility values are in the range of $6 \times 10^{-8} \mathrm{~m}^{3} / \mathrm{kg}-15 \times 10^{-8} \mathrm{~m}^{3} / \mathrm{kg}$. It is estimated that magnetic minerals that contribute to the value of magnetic susceptibility is hematite. Values of magnetic susceptibility in the sinter deposits due to the magnetic minerals (hematite) contain in the sinter deposits. Non water saturated electrical resistivity of sinter deposits are in range of $35.632 \mathrm{\Omega m}$ and $2509.569 \Omega \mathrm{m}$. The large range of electricity resistivity value cause by the absence of conductive minerals in the sinter deposits. Water saturated electrical resistivity of sinter deposits are in range of 6.829 to $49.333 \Omega \mathrm{m}$. The large value of this electric resistivity due to the presence of impurities that are not come from a geothermal reservoir. Value of magnetic susceptibility of sediment samples at three locations increase with decreasing of surface temperatures or when away from the hot springs, while the electrical resistivity has a form of random changes to the temperature decrease.

Keywords: sinter deposits hot spring, electrical resistivity, magnetic susceptibility, geothermal
\end{abstract}

\section{PENDAHULUAN}

Panas bumi merupakan sumber daya energi terbarukan yang ramah lingkungan (clean energy). Panas bumi memiliki jumlah energi yang lebih tinggi dibandingkan dengan energi energi angin dan sel surya dimana tidak bergantung terhadap fluktuasi cuaca dan perubahan iklim (Kagel, dkk., 2007). Salah satu parameter untuk mengetahui potensi panas bumi adalah penentuan temperatur reservoir. Penentuan temperatur reservoir tersebut dapat dilakukan dengan cara pengeboran secara langsung. Metode ini membutuhkan biaya yang sangat mahal. Untuk menghemat biaya, maka dilakukan estimasi temperatur reservoir panas bumi terlebih dahulu. Untuk panas bumi dengan manifestasi berupa mata air panas, estimasi temperatur reservoir dapat dilakukan dengan menggunakan metode geothermometry. Metode ini berdasarkan konsentrasi mineral tertentu yang terkandung di dalam fluida mata air panas. 
Selain itu, estimasi temperatur reservoir panas bumi dapat dilakukan dengan menggunakan data endapan sinter yang terdapat di sekitar mata air panas. Endapan sinter tersebut berasal dari mineral-mineral alterasi hidrotermal yang dibawa oleh fluida lalu mengendap saat di permukaan bumi. Bentuk endapan-endapan sinter terebut dapat berupa endapan sinter silika dan endapan sinter karbonat. Estimasi temperatur reservoir panas bumi ini dilakukan dengan menggunakan Hukum Dakhnov berdasarkan perbandingan antara nilai resistivitas listrik lapisan batuan di reservoir panas bumi dan endapan sinter tersebut (Hersir dan Arnasson, 2010). Wohletz dan Heiken (1992) menyatakan terbentuknya sinter silika di mata air panas menandakan reservoir panas bumi memiliki temperatur tinggi. Keberadaan sinter karbonat di mata air panas menandakan reservoir memiliki temperatur sedang.

Setiap mineral memiliki karakteristik tertentu dan dapat mengalami perubahan oleh parameter tertentu seperti temperatur. Suseptibilitas magnetik dan resistivitas listrik merupakan salah satu sifat fisis dari mineral yang dipengaruhi oleh perubahan temperatur (Schön, 2011). Beberapa peneliti telah melakukan penelitian yang berkaitan dengan sifat fisis endapan sinter di sekitar mata air panas. Masrayanti dkk. (2014) mendapatkan perubahan nilai suseptibilitas magnetik batuan yang berada di mata air panas Ie Jue Aceh Besar berbanding terbalik terhadap perubahan temperatur permukaan. Dona dan Putra (2016) mendapatkan bahwa nilai resistivitas listrik endapan sinter silika jenuh air mengalami perubahan yang berbanding terbalik terhadap perubahan temperatur air di permukaan mata air panas. Endhovani dan Putra (2015) dan Dona dan Putra (2016) mendapatkan hasil XRF bahwa endapan sinter terdiri atas beberapa mineral.

Berdasarkan hal-hal tersebut dilakukan karakterisasi sifat fisis dari endapan sinter yang berada di beberapa sumber mata air panas. Seperti yang diketahui, endapan-endapan sinter yang berada di sekitar mata air panas mengalami paparan temperatur secara terus menerus. Hasil dari karakterisasi sifat fisis tersebut dapat digunakan untuk sebagai data awal dalam mengestimasi temperatur reservoir panas bumi.

\section{METODE}

Peralatan yang digunakan dalam penelitian ini adalah MS2B Bartington Susceptibility Meter, palu dan pahat, neraca digital, Global Positioning System (GPS), komputer, termometer, pipa PVC, multimeter digital, catu daya DC, jangka sorong, elektroda, botol air, plastisin dan plastic kaca. Sampel sinter silika dan sinter karbonat diambil dari sumber mata air panas Sapan Malulung Kabupaten Solok Selatan (SS), Sumani Kabupaten Solok (S) dan Bonjol Kabupaten Pasaman (PT), Sumatera Barat.

Endapan sinter yang dikoleksi adalah endapan yang berada di sekitar mata air panas atau di sepanjang aliran air panas mata air panas. Bentuk pengambilan sampel di aliran air panas dilakukan dengan cara menjauhi sumber mata air panas. Endapan sinter yang didapatkan kemudian dikeringkan di bawah sinar matahari selanjutnya dihancurkan untuk mendapat ukuran yang lebih kecil. Sampel endapan selanjutnya diukur nilai suseptibilitas magnetik menggunakan metode anisotropy of magnetic susceptibility dan resistivitas listrik menggunakan metode dual probe electrode. Sampel endapan sinter yang telah dipisahkan ini dimasukkan ke dalam sample holder dan dipadatkan menggunakan plastisin agar tidak mengalami pergeseran selama pengukuran. Sample holder yang telah berisi sampel endapan sinter dimasukkan ke dalam MS2B Bartington Susceptibility Meter untuk diukur nilai suseptibilitas mangetiknya dengan orientasi sebanyak 15 arah yang dibantu oleh software Multisus untuk memperoleh data suseptibilitas magnetiknya.

Pengukuran nilai resistivitas dilakukan dalam dua keadaan, yaitu jenuh air dan tidak jenuh air. Sampel endapan sinter dimasukkan ke dalam pipa PVC dengan diameter 2 inch dan direndam dengan air sampai keadaan jenuh dimana telah diketahui geometri luas $(A)$ dan panjangnya $(L)$. Sampel di dalam pipa PVC diberikan beda potensial, selanjutnya nilai arus listrik yang didapatkan diregresikan terhadap beda potensial untuk mendapatkan nilai resistansi listrik $(R)$. Nilai resistivitas listrik $(\rho)$ dapat dihitung dengan menggunakan Persamaan (1) dengan menginputkan nilai resistansi listrik dan geometri pipa PVC. Pengukuran resistivitas listrik tidak jenuh air menggunkan metode yang dengan metode jenuh air, namun langkah perendaman sampel dengan air tidak disertakan dalam penelitian. 


$$
\rho=\frac{R A}{L}
$$

Nilai suseptibilitas magnetik, resistivitas listrik tidak jenuh air dan jenuh air yang telah didapatkan dari masing-masing sampel dibandingkan satu sama lain.

\section{HASIL DAN DISKUSI}

\subsection{Suseptibilitas Magnetik Endapan Sinter}

Hasil perhitungan nilai suseptibilitas magnetik sampel untuk setiap lokasi adalah seperti pada Tabel 1. Nilai suseptibilitas magnetik yang didapatkan berkisar dari $6,447 \times 10^{-8}-14,433$ x $10^{-8} \mathrm{~m}^{3} / \mathrm{kg}$.

Tabel 1 Nilai suseptibilitas magnetik endapan sinter

\begin{tabular}{lcrrrrr}
\hline \multirow{2}{*}{$\begin{array}{c}\text { Lokasi Mata } \\
\text { Air Panas }\end{array}$} & Temperatur Mata & \multicolumn{5}{c}{ Suseptibilitas Magnetik $\left(10^{-8} \mathrm{~m}^{3} / \mathrm{kg}\right)$} \\
\cline { 3 - 7 } & Air Panas $\left({ }^{\circ} \mathrm{C}\right)$ & \multicolumn{1}{c}{1} & \multicolumn{1}{c}{2} & \multicolumn{1}{c}{3} & \multicolumn{1}{c}{4} \\
\hline SS_MP_001 & 87 & 12,167 & 13,220 & 13,627 & 14,053 & 14,433 \\
SS_MP_002 & 80 & 8,187 & 10,320 & 11,333 & 12,400 & 14,100 \\
SS_MP_003 & 91 & 10,280 & 10,527 & 11,593 & 11,893 & 14,207 \\
S_MP_001 & 44 & 8,627 & 9,933 & 10,973 & 11,780 & 12,240 \\
S_MP_002 & 45 & 8,460 & 9,353 & 9,413 & 12,487 & 14,173 \\
PT_MP_001 & 85 & 7,873 & 8,093 & 8,260 & 8,380 & 8,973 \\
PT_MP_002 & 45 & 6,447 & 6,793 & 6,913 & 8,320 & 9,940 \\
PT_MP_003 & 67 & 7,713 & 11,387 & 13,313 & 13,440 & 14,113 \\
\hline
\end{tabular}

Grafik hubungan suseptibilitas magnetik terhadap posisi dari sumber mata air panas ditampilkan pada Gambar 1. Dari Gambar 1 dapat dilihat bahwa nilai suseptibilitas magnetik endapan sinter semakin besar terhadap jarak dari sumber mata air panas atau penurunan temperatur permukaan.

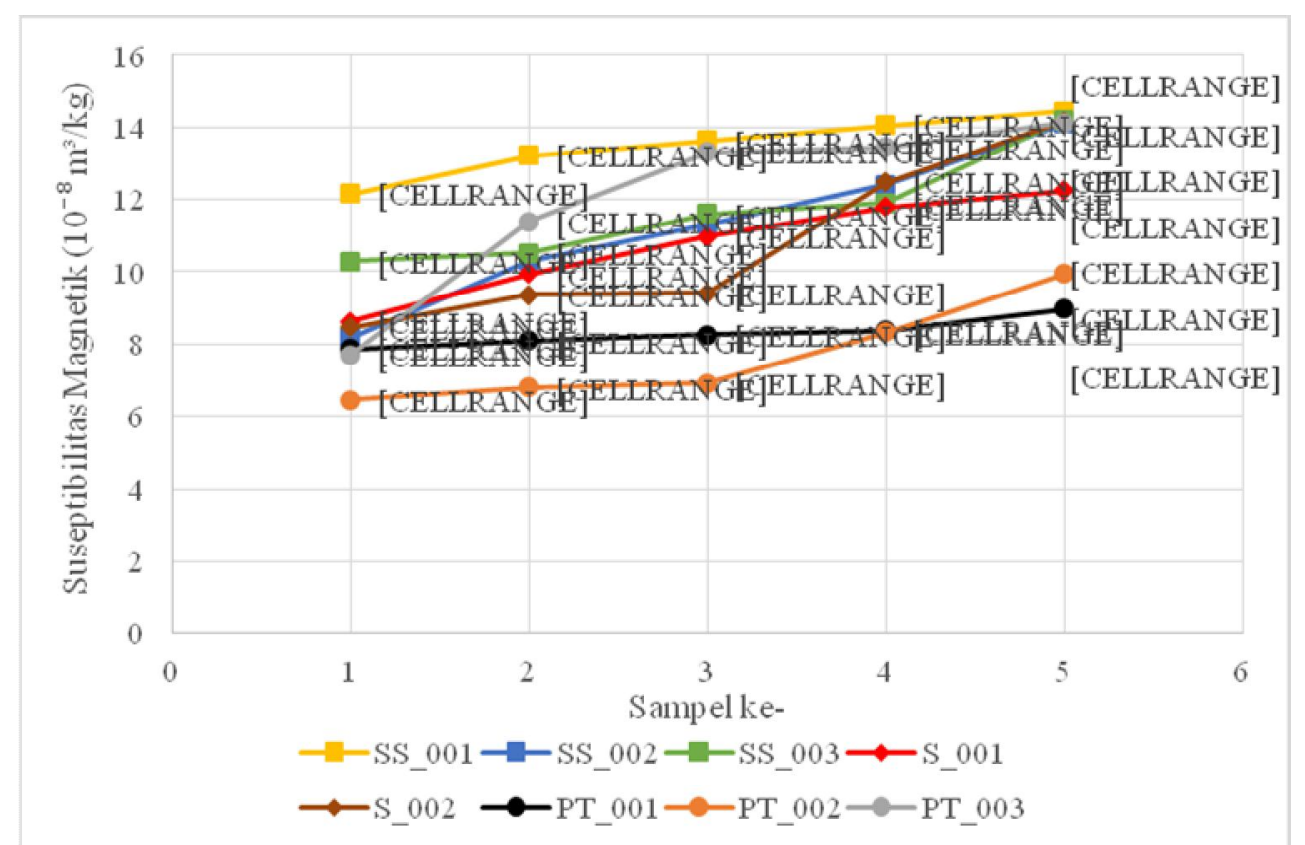

Gambar 1 Hubungan nilai suseptibilitas magnetik endapan sinter terhadap posisi sampel untuk 8 mata air panas dengan temperatur yang berbeda

Nilai suseptibilitas magnetik yang didapatkan tidak semuanya mengikuti asas Temperatur Curie. Keadaan ini didapatkan dengan nilai suseptibilitas magnetik yang lebih besar 
pada temperatur yang tinggi, seperti SS_001 dan SS_003. Dua endapan tersebut memiliki nilai suseptibilitas magnetik yang tinggi dibandingkan dengan endapan dengan temperatur yang lebih rendah. Fenomena tersebut dapat disebabkan oleh beberapa hal, yaitu komposisi mineral yang terkandung di dalam endapan. Hal ini disebabkan oleh jumlah komposisi mineral magnetik yang terdapat pada endapan sinter tergolong sedikit. Berdasarkan nilai hasil XRF, hematit diperkirakan sebagai penyebab dari nilai suseptibilitas magnetik endapan sinter menjadi positif. Tarling dan Hrouda (1993) menyatakan hematit tergolong sebagai mineral ferromagnetik. Nilai suseptibilitas magnetik dari hematit berkisar $25 \times 10^{-8} \mathrm{~m}^{3} / \mathrm{kg}$. Didapatkan perbedaan antara nilai suseptibilitas magnetik endapan sinter terhadap nilai suseptibilitas hematit berdasarkan literatur. Perbedaan ini dapat disebabkan oleh proses demagnetisasi oleh temperatur saat mineral berada di reservoir panas bumi.

\subsection{Resistivitas Listrik Tidak Jenuh Air Endapan Sinter}

Hasil perhitungan nilai resistivitas listrik tidak jenuh air sampel untuk setiap lokasi adalah seperti pada Tabel 2. Nilai resistivitas listrik yang didapatkan berkisar di antara $35 \Omega \mathrm{m}$ dan $2510 \Omega \mathrm{m}$. Nilai resistivitas listrik terendah dan tertinggi yaitu $35,632 \Omega \mathrm{m}$ dan $2509,569 \Omega \mathrm{m}$ didapatkan pada sampel SS_001_02 dan SS_003_03. Terdapat perbedaan yang sangat jauh antara nilai resistivitas listrik terendah dan tertinggi. Nilai rata-rata resistivitas listrik yang didapatkan bernilai 550,276 $\Omega \mathrm{m}$. Terdapat 37,5 \% (15 buah) sampel memiliki nilai resistivitas listik di antara $10 \Omega \mathrm{m}-100 \Omega \mathrm{m}, 25 \%$ (10 buah) sampel memiliki nilai resistivitas listrik di antara $100 \Omega \mathrm{m}$ dan $200 \Omega \mathrm{m}, 20 \%$ (8 buah) sampel memiliki nilai resistivitas listrik di antara $200 \Omega \mathrm{m}$ dan $1000 \Omega \mathrm{m}$ dan $17,5 \%$ (7 buah) sampel memiliki nilai resistivitas di atas $1000 \Omega \mathrm{m}$. Endapan dengan nilai resistivitas listrik di bawah $100 \Omega \mathrm{m}$, tegangan listriknya masih memiliki hubungan yang linear terhadap kuat arus. Hubungan linear antara dua parameter tersebut masih dapat ditemukan pada sampel yang memiliki nilai resistivitas listrik diantara $100 \Omega \mathrm{m}-200 \Omega \mathrm{m}$. Ketidaklinearan antara dua parameter ini mulai terjadi saat nilai resistivitas listrik berada di atas $200 \Omega \mathrm{m}$. Semakin besar nilai resistivitas listrik yang didapatkan dari sampel, hubungan antara tegangan dan kuat arus listrik semakin jauh menjadi linear.

Tabel 2 Nilai resistivitas listrik tidak jenuh air endapan sinter

\begin{tabular}{lcrrrrr}
\hline \multirow{2}{*}{$\begin{array}{c}\text { Lokasi Mata } \\
\text { Air Panas }\end{array}$} & $\begin{array}{c}\text { Temperatur Mata } \\
\text { Air Panas }\left({ }^{\circ} \mathrm{C}\right)\end{array}$ & \multicolumn{5}{c}{ Resistivitas Listrik $(\Omega \mathrm{m})$} \\
\cline { 3 - 7 } SS_001 & 87 & 158,683 & 112,843 & 508,891 & 361,100 & 420,460 \\
SS_002 & 80 & 59,682 & 61,239 & 49,508 & 98,158 & 372,438 \\
SS_003 & 91 & 2383,036 & 2108,411 & 2509,569 & 2444,666 & 2305,539 \\
S_001 & 44 & 84,306 & 35,632 & 42,156 & 59,581 & 45,481 \\
S_002 & 45 & 167,661 & 816,396 & 1178,091 & 225,706 & 143,435 \\
PT_001 & 85 & 660,515 & 716,178 & 195,343 & 402,356 & 2353,371 \\
PT_002 & 45 & 126,735 & 116,984 & 136,949 & 140,884 & 70,798 \\
PT_003 & 67 & 76,505 & 97,057 & 64,802 & 58,608 & 41,286 \\
\hline
\end{tabular}

Ketidaklinearan tegangan dan kuat arus listrik ini dapat disebabkan oleh bahan-bahan isolator yang terdapat di dalam sampel. Berdasarkan Endhovani dan Putra (2015) dan Dona dan Putra (2016), di dalam endapan sinter didominasi oleh bahan-bahan isolator dan keberadaan bahan konduktor hanya menjadi minoritas. Keadaan inilah yang menyebabkan didapatkannya nilai resistivitas yang sangat tinggi pada beberapa endapan sinter dengan nilai diatas $500 \Omega \mathrm{m}$.

Grafik hubungan resistivitas listrik tidak jenuh air terhadap posisi dari sumber mata air panas ditampilkan pada Gambar 2. Dari Gambar 2 dapat dilihat bahwa nilai resistivitas listrik tidak jenuh air berubah secara acak terhadap perubahan temperatur sampel. Secara teori, nilai resistivitas listrik bersifat sebanding terhadap perubahan temperatur. Contohnya adalah resistivitas listrik yang didapatkan dari SS_003 dengan temperatur mata air panas tertinggi, nilai resistivitas listrik di titik pertama harus memiliki nilai resistivitas listrik tertinggi. Keadaan ini tidak terpenuhi karena nilai tertinggi didapatkan dari titik ketiga. Nilai resistivitas terendah juga 122 
tidak didapatkan oleh titik kelima, namun dimiliki oleh titik kedua. Keanehan pada umunya didapatkan oleh setiap sampel endapan. Keanehan ini kemungkinan disebabkan oleh keberadaan mineral konduktif yang terdapat di dalam endapan sinter.

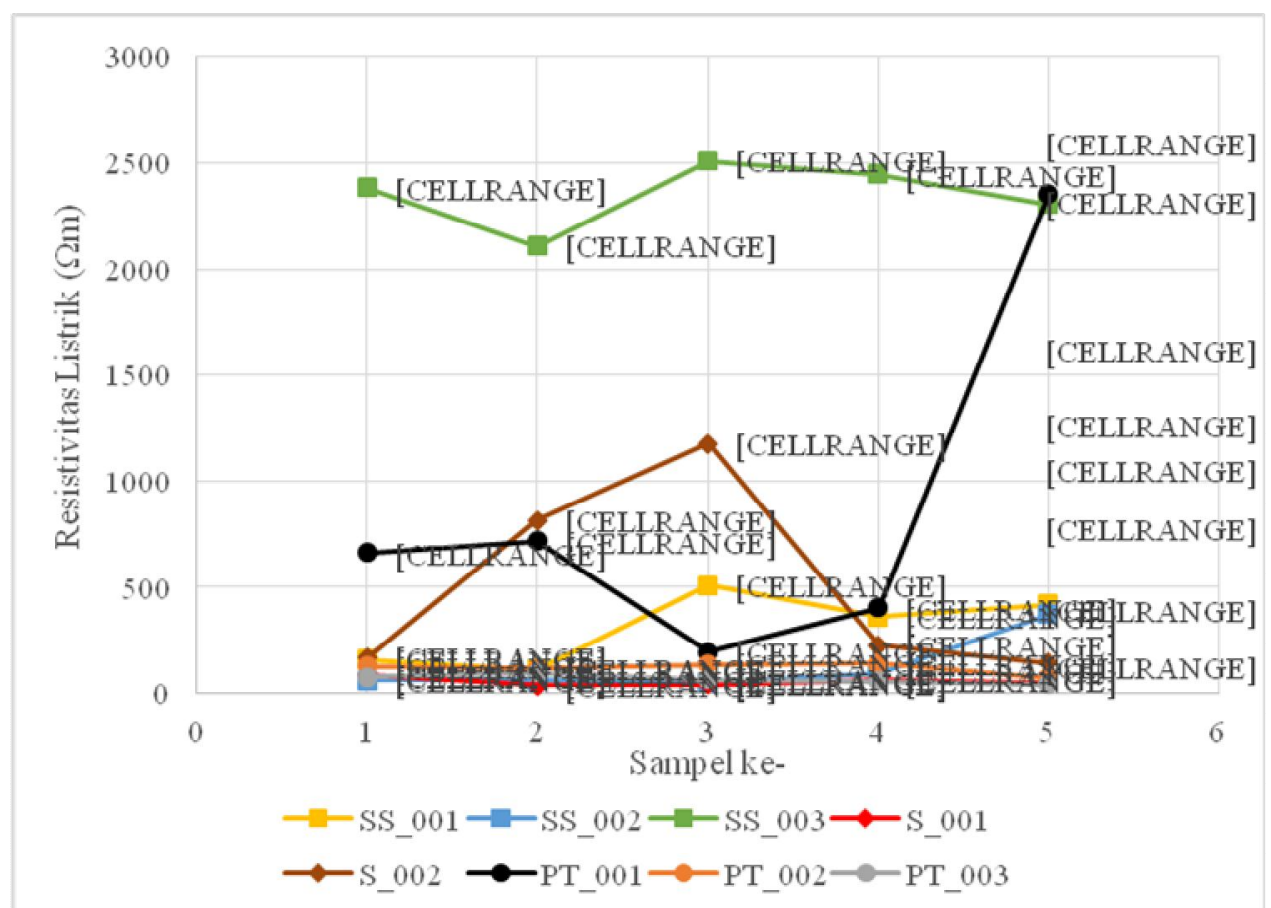

Gambar 2 Hubungan nilai resistivitas listrik tidak jenuh air endapan sinter terhadap posisi sampel untuk 8 mata air panas dengan temperatur yang berbeda

\subsection{Resistivitas Listri Jenuh Air Endapan Sinter}

Hasil perhitungan nilai resistivitas listrik tidak jenuh air sampel untuk setiap lokasi adalah seperti pada Tabel 3. Nilai resistivitas listrik jenuh air yang didapatkan berkisar di antara $6,829 \Omega \mathrm{m}$ dan $49,333 \Omega \mathrm{m}$. Nilai rata-rata resistivitas listrik jenuh air yang didapatkan bernilai $13,817 \Omega \mathrm{m}$. Terdapat perbedaan yang sangat jauh antara nilai resistivitas listrik jenuh air terendah dan tertinggi. Terdapat 32,5\% (13 buah) sampel memiliki nilai resistivitas listik jenuh air di bawah $10 \Omega \mathrm{m}, 55 \%$ (22 buah) sampel memiliki nilai resistivitas listrik jenuh air diantara $10 \Omega \mathrm{m}$ dan $20 \Omega \mathrm{m}$ dan $12,5 \%$ (5 buah) sampel memiliki nilai resistivitas jenuh air diantara 20 $\Omega \mathrm{m}$ dan $50 \Omega \mathrm{m}$.

Tabel 3 Nilai resistivitas listrik jenuh air endapan sinter

\begin{tabular}{|c|c|c|c|c|c|c|}
\hline \multirow{2}{*}{$\begin{array}{l}\text { Lokasi Mata } \\
\text { Air Panas }\end{array}$} & \multirow{2}{*}{$\begin{array}{l}\text { Temperatur Mata } \\
\text { Air Panas }\left({ }^{\circ} \mathrm{C}\right)\end{array}$} & \multicolumn{5}{|c|}{ Resistivitas Listrik $(\Omega \mathrm{m})$} \\
\hline & & 1 & 2 & 3 & 4 & 5 \\
\hline SS_001 & 87 & 8,819 & 10,671 & 14,164 & 49,933 & 34,639 \\
\hline SS_002 & 80 & 16,188 & 13,992 & 8,525 & 10,253 & 11,16 \\
\hline SS_003 & 91 & 8,909 & 8,917 & 13,966 & 11,813 & 12,972 \\
\hline S_001 & 44 & 14,038 & 20,559 & 12,202 & 26,636 & 19,463 \\
\hline S_002 & 45 & 9,279 & 14,243 & 27,436 & 14,526 & 15,389 \\
\hline PT_001 & 85 & 7,353 & 8,895 & 12,725 & 11,12 & 10,915 \\
\hline PT_002 & 45 & 11,504 & 6,829 & 9,479 & 10,132 & 12,491 \\
\hline PT_003 & 67 & 8,002 & 8,465 & 7,446 & 10,015 & 8,635 \\
\hline
\end{tabular}




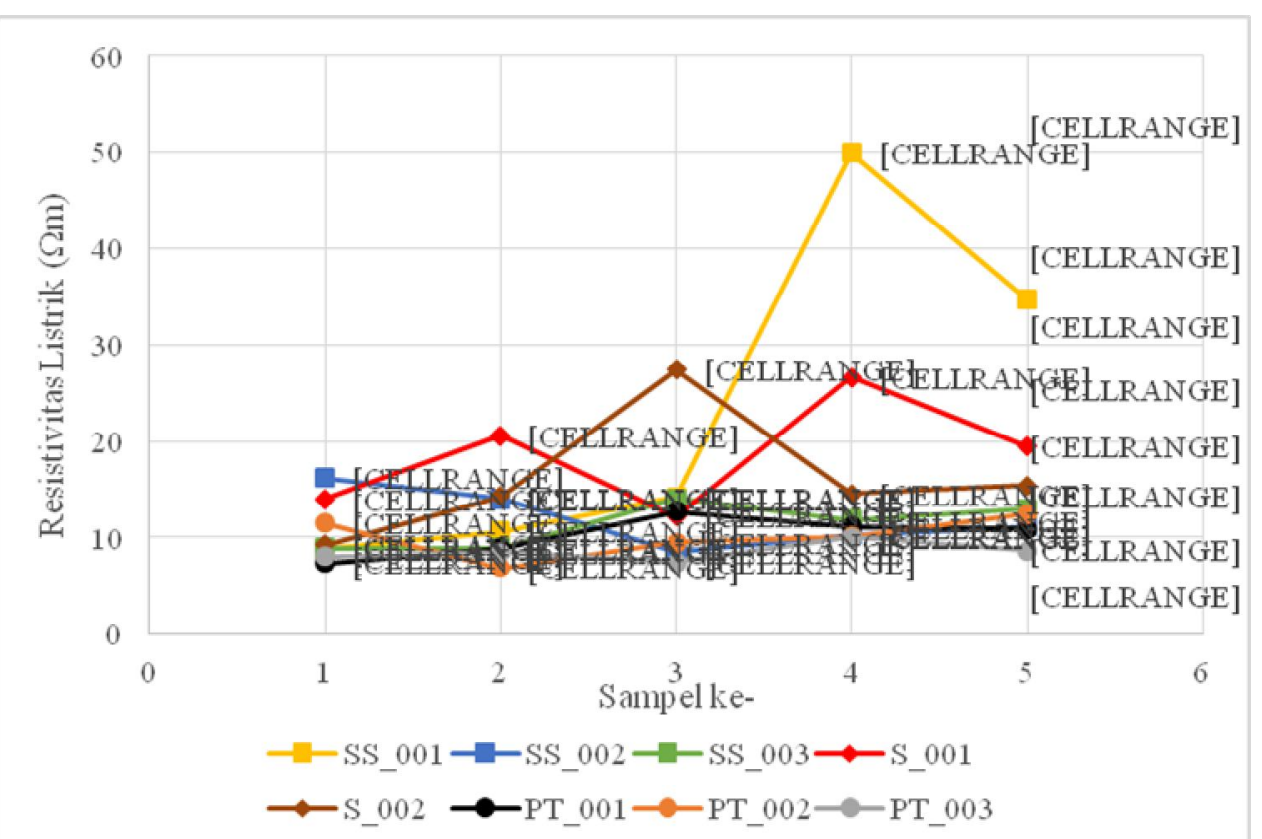

Gambar 3 Hubungan nilai resistivitas listrik jenuh air endapan sinter terhadap posisi sampel untuk 8 mata air panas dengan temperatur yang berbeda

Grafik hubungan resistivitas listrik jenuh air terhadap posisi dari sumber mata air panas dapat dilihat pada Gambar 3. Dari Gambar 3 dapat dilihat bahwa perubahan nilai resistivitas listrik jenuh air memiliki pola acak terhadap perubahan temperatur permukaan mata air panas. Secara teori, nilai resistivitas listrik jenuh air bersifat berbanding terbalik terhadap naiknya temperatur (Hersir dan Arnasson, 2010). Contohnya adalah resistivitas listrik yang didapatkan dari SS_001, nilai resistivitas listrik bertambah terhadap turunnya temperatur permukaan pada endapan. Peningkatan nilai resistivitas listrik didapatkan hingga sampel keempat. Nilai resistivitas pada sampel kelima didapatkan menurun dibandingkan sampel sebelumnya. Sampel SS_001 didapatkan dua sampel yang memiliki selisih nilai resistivitas listrik sangat jauh, yaitu sampel keempat dan sampel kelima. Secara fisik, sampel SS_001_04 dan SS_001_05 didominasi oleh serpihan-serpihan kayu dimana kayu merupakan salah satu bahan isolator. Keadaan ini dapat menyebabkan tingginya nilai resistivitas listrik sampel dan membentuk anomali karena banyaknya jumlah sinter silika yang mengalami pengendapan.

\section{KESIMPULAN}

Berdasarkan hasil karakterisasi sifat magnetik dan sifat listrik endapan sinter didapatkan beberapa intisari berupa nilai suseptibilitas magnetik yang didapatkan dari seluruh endapan sampel adalah $6 \times 10^{-8} \mathrm{~m}^{3} / \mathrm{kg}-15 \times 10^{-8} \mathrm{~m}^{3} / \mathrm{kg}$. Diperkirakan mineral magnetik yang berkontribusi di dalam nilai suseptibilitas magnetik adalah hematit. Bentuk variasi nilai suseptibilitas magnetik di dalam endapan sinter dikarenakan oleh komposisi mineral magneti (hematit) yang terkandung di dalam endapan sinter.

Nilai resistivitas listrik tidak jenuh air didapatkan pada kisaran 35,632 $\Omega \mathrm{m}$ dan $2509,569 \Omega \mathrm{m}$. Besarnya rentang nilai resistvitas listrik yang didapatkan karena pada beberapa sampel bersifat resistif disebabkan oleh ketiadaan mineral konduktif di dalam endapan sinter.

Nilai resistivitas listrik jenuh air didapatkan pada kisaran 6,829 $\Omega \mathrm{m}$ sampai 49,333 $\Omega \mathrm{m}$. Tingginya nilai resistvitas listrik ini dikarenakan terdapatnya material-material pengotor yang tidak berasal dari reservoir panas bumi.

Nilai suseptibilitas magnetik endapan sampel pada ketiga lokasi meningkat terhadap penurunan temperatur permukaan atau bila menjauhi mata air panas, sedangkan resistivitas listrik memiliki bentuk perubahan yang acak terhadap penurunan temperatur. 


\section{DAFTAR PUSTAKA}

Arnasson, K., Karlsdottir, R., Eysteinsson, H., Flovenz, O. G. dan Gudlaugsson, T., 2000, The Resistivity Structure of High-Temperatur Geothermal Systems in Iceland, Proceedings World Geothermal Congress 2000, June 2010, Japan.

Dona, R. M. dan Putra, A., 2016, Hubungan Karakteristik Sinter Silika dan Temperatur Permukaan Mata Air Panas (Studi Kasus: Mata Air Panas Bawah Kubang, Garara dan Bukik Gadang di Kabupaten Solok), Jurnal Fisika Unand (JFU), Vol.5, No.3, Jur. Fisika Unand.

Endhovani, R. dan Putra, A., 2015, Analisa Konduktivitas Termal dan Porositas Sinter Silika Sumber Mata Air Panas di Sapan Malulung, Kecamatan Alam Pauh Duo, Kabupaten Solok Selatan, Jurnal Fisika Unand (JFU), Vol.5, No.1, Jur. Fisika Unand.

Hersir, G. P. dan Arnasson, K., 2010, Resistivity of Rocks, Short Course V on Exploration for Geothermal Resources, UNU-GTP, GDC dan KenGen, Kenya.

Kagel, A., Bates, D. dan Gawell, K., 2007, A guide to Geothermal Energy and The Enviroment, Geothermal Energy Association, United States of America.

Kebede, Y., 2001, Application of The Resistivity Method in the Krisuvik Geothermal Area, Reykjanes Peninsula SW-Iceland, Geothermal Training Programme, The United Nations University, Iceland.

Lagat, J., 2009, Hydrothermal Alteration Mineralogy in Geothermal Fields with Case Examples from Olkaria Domes Geothermal Field, Kenya, Short Course IV on Exploration for Geothermal Resources, UNU-GTP, Kengen and GDC.

Masrayanti, I., Syukri, M. dan Jalil, Z., 2014, Analisa Sifat Suseptibilitas Magnetik Batuan pada Daerah Geotermal di Kawasan Ie Jue, Aceh Besar, Skripsi, Fakultas Matematika dan Ilmu Pengetahuan Alam, Universitas Syiah Kuala, Banda Aceh.

Pentecost, A., 2005, Travertine, Springer, Netherland.

Rimstidt, J., D. dan Cole, D., R., 1982, The Mechanism of Formation of The Beowawe, Nevada Siliceous Sinter Deposit, Geothermal Mineralization I, U.S Department Of Energy: Division of Geothermal Energy, Nevada.

Schön, J.H., 2011, Physical Propoerties of Rocks, Elsevier Ltd, Netherlands.

Tarling, D.H. dan Hrouda, F., 1993, The Magnetic Anisotropy of Rocks, Chapman \& Hall, London, Inggris.

Wohletz, K. dan Heiken, G., 1992, Volcanology and Geothermal Energy, University of California Press, Barkeley, United States of America. 